\title{
Effect of carbon on wettability and interface reaction between melt superalloy and ceramic material
}

\author{
Xiaoyan Chen, Yizhou Zhou ${ }^{\mathrm{a}}$, Tao Jin, and Xiaofeng Sun \\ Institute of Metal Research, Chinese Academy of Sciences, Shenyang, China
}

\begin{abstract}
Effect of $\mathrm{C}$ on wettability and interface reaction between a nickel based superalloy and ceramic material was investigated by using a sessile drop method. It was found that the content of $\mathrm{C}$ in the alloy is able to influence the wettability and interface reaction. Alloys with $\mathrm{C}$ content lower than $0.1 \mathrm{wt} . \%$ are stable on ceramic material and no interface reaction generates at the alloy-ceramic interface. However, when $\mathrm{C}$ content is higher than $0.1 \mathrm{wt} . \%$, the interface reaction occurs and the wetting angle decreases quickly. The product of interface reaction is discontinuous and composed of $9 \mathrm{Al}_{2} \mathrm{O}_{3} \cdot \mathrm{Cr}_{2} \mathrm{O}_{3}$. Such result indicates that $\mathrm{Cr}$ in the alloy is impossible to react with the ceramic material and form $\mathrm{Cr}_{2} \mathrm{O}_{3}$ without the assistance of $\mathrm{C}$. It is suggested that $\mathrm{C}$ in the alloy deoxidizes $\mathrm{SiO}_{2}$ in the ceramic material and produces $\mathrm{SiO}$ and $\mathrm{CO} . \mathrm{SiO}$ is unstable and it can release active $\mathrm{O}$ atom at the interface. $\mathrm{Cr}$ at the interface combines with free $\mathrm{O}$ atom and forms $\mathrm{Cr}_{2} \mathrm{O}_{3} \cdot \mathrm{Al}_{2} \mathrm{O}_{3}$ in the ceramic material and $\mathrm{Cr}_{2} \mathrm{O}_{3}$ finally forms $9 \mathrm{Al}_{2} \mathrm{O}_{3} \cdot \mathrm{Cr}_{2} \mathrm{O}_{3}$.
\end{abstract}

\section{Introduction}

During investment casting of superalloys, the melt alloy contacts with ceramic mould in the entire solidification process. The surface quality of the casting is affected by wettability between the melt alloy and ceramic material. As the melt alloy wets the ceramic materials well, the melt can infiltrate into ceramic mould through the capillaries on the mould and then sand penetrations and inclusions develop on the surface of the casting. When the casting temperature and alloy composition fulfill the thermodynamic conditions of interface reaction, reaction occurs between melt alloy and ceramic materials, leading to reaction layers on the surface of the casting and destroying the surface quality of the casting. Therefore, there is great interest in the industry to eliminate or to minimize interface reaction.

Active elements such as $\mathrm{C}, \mathrm{Hf}, \mathrm{Cr}, \mathrm{Al}$ and $\mathrm{Ti}$ in superalloys have been found to promote the reaction between the melt alloy and the ceramic mould and result in surface defects. $\mathrm{Li}$ et al. reported that $\mathrm{Cr}$ and $\mathrm{Hf}$ accelerated interface reaction at high temperature and the reaction product was mainly composed of $\mathrm{HfO}_{2}$ and $\mathrm{Al}_{2} \mathrm{O}_{3}$ [1]. Zheng pointed out that $\mathrm{Cr}, \mathrm{Al}$ and $\mathrm{Ti}$ in superalloys reacted with silicon oxide, forming $\mathrm{Cr}_{2} \mathrm{O}_{3}$ and inducing some metallic nodular protrusions on the surface of alloys [2]. Valenza et al. studied the wettability and interface reaction of superalloys on different ceramic substrates by using the "sessile drop" method [3]. Although the reaction product and the wetting angle were studied in details, the relationship between wettability and interface reaction was not clarified in [3].

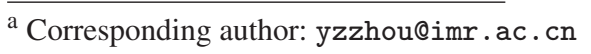

Orlov et al. found that $\mathrm{CO}$ bubbles were produced because $\mathrm{C}$ in superalloys reacts with ceramic mould. $\mathrm{CO}$ could result in porosities after the casting was solidified. As a result, the fatigue strength of the castings is reduced [4]. The relationship between wettability and interface reaction has also not been studied in [4].

$\mathrm{C}$ plays an important role in strengthening of grain boundaries by precipitating carbides in superalloys. However, the content of $\mathrm{C}$ should be strictly controlled because $\mathrm{C}$ is an active element promoting reaction between melt alloy and ceramic materials. The purpose of the present work is to study the wettability and interface reaction between ceramic material and a Ni-based superalloy with different $\mathrm{C}$ content. When the interface reaction caused by $\mathrm{C}$ is needed to control, a reasonable composition range can be figured out from the present study.

\section{Materials and experimental methods}

To study of the effect of $\mathrm{C}$ content on wettabilty and interface reaction, superalloys with different $\mathrm{C}$ contents were prepared by an induction furnace. The main composition of the alloy (mass fraction, \%) was $\mathrm{Cr} 4.37$, Co 8.92, W 7.5, Mo 2.02, Al 5.72, Nb 1.05, Ta 6.7, Re 2.02, $\mathrm{Hf} 0.09$ and $\mathrm{Ni}$ in balance. The content of $\mathrm{C}$ (mass fraction, $\%$ ) was $0.008,0.01,0.05,0.1,0.2$ and 0.3 , respectively. Alloys were cut into $0.15 \mathrm{~g}$ weight cubes for in-situ sessile drop experiments and $5 \mathrm{~mm} \times 5 \mathrm{~mm} \times 5 \mathrm{~mm}$ cubes for non-in-situ experiments. The ceramic substrates sized of $20 \mathrm{~mm}$ long, $20 \mathrm{~mm}$ wide and $6 \mathrm{~mm}$ thick were cut from a ceramic shell which was made by the general procedure for preparation of ceramic moulds in investment casting. The slurry used to make the ceramic shell was composed 

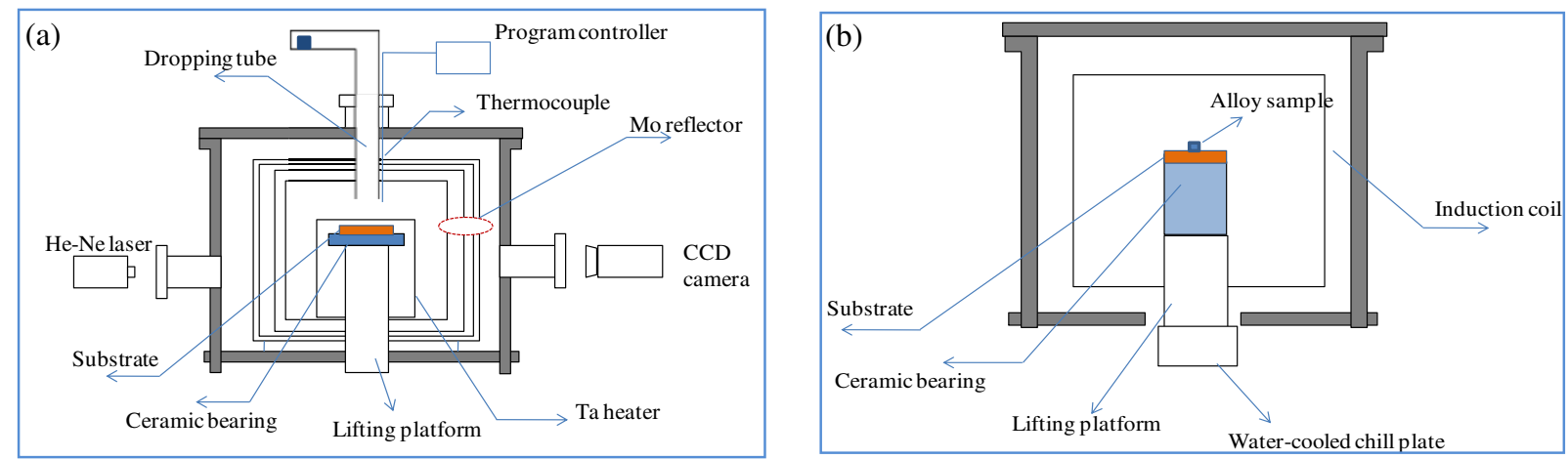

Figure 1. Schematic diagram showing the sessile drop experiments (a) in-situ sessile drop experiments (b) non-in-situ sessile drop experiments.
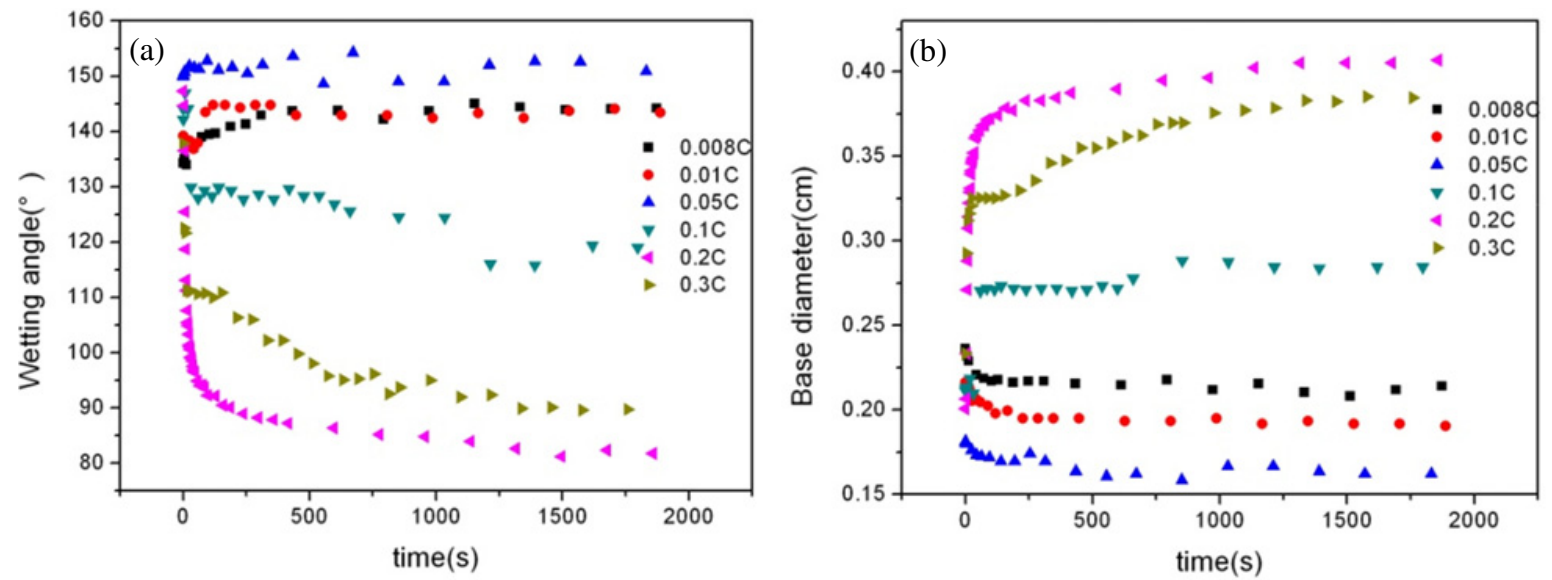

Figure 2. Dependence of wetting angles (a) and base diameters (b) of each alloy drop on the wetting time in the in-situ experiment.

of 95 wt. $\% \mathrm{Al}_{2} \mathrm{O}_{3}+5 \mathrm{wt} . \% \mathrm{SiO}_{2}$ ceramic powders and colloidal silica with $30 \% \quad \mathrm{SiO}_{2}$ content as refractory material and binder, respectively. The alloy samples were polished to remove the oxides on the surface and then ultrasonically cleaned in acetone. The ceramic substrates were ultrasonically cleaned in acetone.

In-situ sessile drop experiments to determine the wetting angle were carried out in a high temperature furnace with observation windows from which the photos of the melt alloy could be recorded using a high speed camera outside of the furnace (Fig. 1a). Ceramic substrate was preplaced on an alumina support inside the stainless steel chamber. The alloy sample was stored in a metal tube outside of the furnace. The metal tube was connected to the alumina tube through which the alloy could be directly transferred to the ceramic substrate. As the vacuum in the chamber reached $10^{-4} \mathrm{~Pa}$, the furnace was heated to the experiment temperature at $1823 \mathrm{~K}$. After the temperature and the atmosphere were stabilized, the alloy sample was dropped through the alumina tube and remained on the ceramic substrate. The sample melted and the melt remained for $20 \mathrm{~min}$ at the constant temperature. Highresolution photographs of the melt profile were taken by a charge coupled device (CCD) camera. Geometric parameters of the melt drop were directly calculated and from the drop profiles wetting angle was calculated on the base of Laplace equation.
Non-in-situ sessile drop experiments were carried out in the vacuum directional solidification furnace (Fig. 1b). The alloy samples were placed on the ceramic substrates and they were rested in the intermediate height of the furnace. As the vacuum in the furnace reached $0.01 \mathrm{~Pa}$, the furnace was heated to the experiment temperature at $1823 \mathrm{~K}$ and kept $20 \mathrm{~min}$ to melt the alloy samples. After the alloy samples were solidified, the wetting angle $\theta$ was calculated according to the formula of $\theta=2 \arctan (2 \mathrm{~h} / \mathrm{d})$, where $\mathrm{h}$ is the drop height and $\mathrm{d}$ is base diameter of the drop.

After experiments, the interfacial microstructures of the samples were examined by using a scanning electron microscope (SEM, JMS-6301F, Japan) and the phase of reaction product was analyzed by X-ray diffraction (XRD, D/Max 2500PC, Japan).

\section{Results}

Figure 2 shows the dependence of wetting angles and base diameters of each alloy drop on the wetting time in the insitu experiments. As is shown, the wetting behavior and final steady wetting angle are influenced by $\mathrm{C}$ content. When $\mathrm{C}$ content is $0.008,0.01$ and $0.05 \mathrm{wt} . \%$, the wetting angle and base diameter of the drops are independent of the wetting time and the wetting angles are all around $140^{\circ}$. When $\mathrm{C}$ content is $0.1 \mathrm{wt} . \%$, the wetting angle 


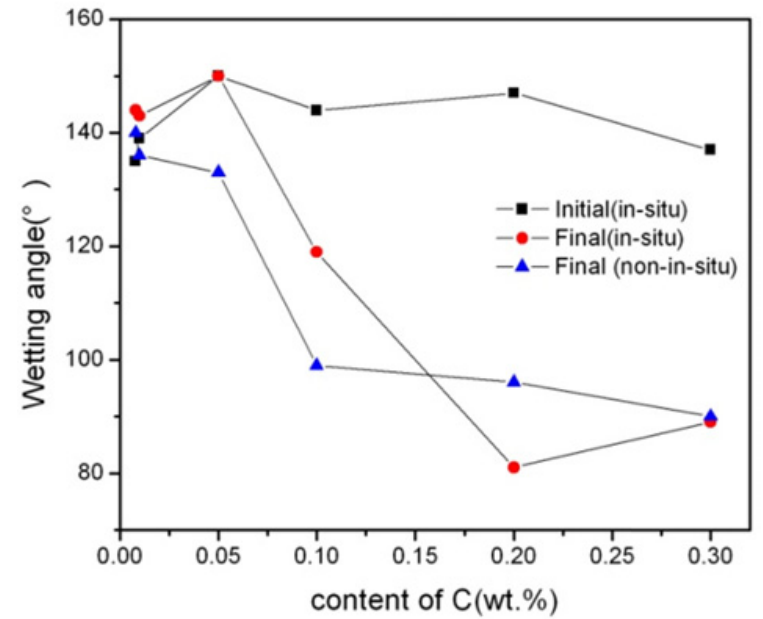

Figure 3. Comparison of wetting angles in the in-situ and nonin-situ sessile drop experiments.
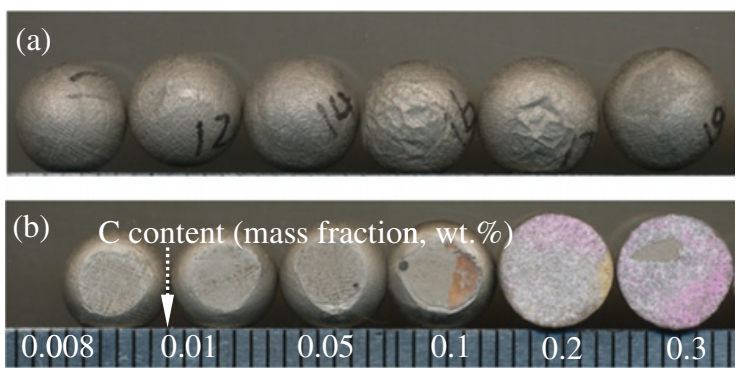

Figure 4. Top-view (a) and under-view (b) images of each solidified alloy drop from non-in-situ experiments.

decreases to $119^{\circ}$ and the base diameter increases a little. When $\mathrm{C}$ content is 0.2 and $0.3 \mathrm{wt} . \%$, the wetting angle and base diameter of the drops vary quickly with the wetting time and the wetting angle decreases to $81^{\circ}$ and $89^{\circ}$, respectively. In addition, some gas released from the alloy drop which can be seen through the observation windows in the case of 0.2 and $0.3 \mathrm{wt} . \% \mathrm{C}$.

The initial and the final steady wetting angles obtained by in-situ experiments and the final steady wetting angles obtained by non-in-situ experiments are compared in Fig. 3. In in-situ experiments, the initial wetting angles of each alloy drop with different $\mathrm{C}$ contents are almost the same, while the final steady wetting angles are different. The final steady wetting angles from non-in-situ studies show the same tendency as that in in-situ studies. The little difference of the final steady wetting angles from non-in-situ and in-situ studies is ascribed to the different vacuum level in the furnace and different weight of alloy samples.

Figure 4 shows top view and under view images of each alloy drop with different $\mathrm{C}$ contents. The alloy melt with $0.008,0.01$ and 0.05 wt. $\% \mathrm{C}$ form regular spheres after solidification and no interaction product appears at the metal-ceramic interface. As $\mathrm{C}$ content is $0.1 \mathrm{wt} \%$, the base diameter of alloy drop is a little greater than those with less $\mathrm{C}$ content and some yellow products can be seen at the metal-ceramic interface. The alloy drops with 0.2 and 0.3 wt.\% $\mathrm{C}$ have larger base diameters after solidification and purple product can be seen at the interface. It is clear that $0.1 \mathrm{wt} \% \mathrm{C}$ content is critical for the interface reaction between the melt and ceramic material. As $\mathrm{C}$ content is higher than $0.1 \mathrm{wt} \%$, the interface reaction takes place and the wetting angle decreases greatly.

Figure 5 shows the microstructure on alloy drop bottom and ceramic surface. Some white materials, which are stripped from the ceramic surface, cover on the alloy drop bottom with 0.1 wt.\% C (Fig. 5a). There are some globular residues on the corresponding ceramic surface after the alloy drop is departed from the ceramic substrate. The globular residue may come from the melt alloy (Fig. 5b). In the case of $0.2 \mathrm{wt} . \% \mathrm{C}$, the alloy drop bottom is covered by a great number of white material (Fig. 5c). On the corresponding ceramic surface, a clear boundary divides the surface into two areas. There is no interface reaction in area 1 but severe interface reaction in area 2, as is marked by the dashed curve in Fig. $5 \mathrm{~d}$.

For alloy with 0.1 wt.\% C, the interface between the alloy drop and ceramic material is flat and no penetration or reaction layer can be seen at the interface, as is shown in Fig. 6a. For alloy with 0.2 wt.\% C, a $50 \sim 100 \mu \mathrm{m}$ thick reaction layer is observed at the interface (Fig. 6b). Based on the XRD analysis (Fig. 7), the reaction product is identified to be $9 \mathrm{Al}_{2} \mathrm{O}_{3} \cdot \mathrm{Cr}_{2} \mathrm{O}_{3}$, which indicates that $\mathrm{Cr}$ in the melt alloy reacts with ceramic substrate and forms $\mathrm{Cr}_{2} \mathrm{O}_{3} \cdot \mathrm{Cr}_{2} \mathrm{O}_{3}$ combines with $\mathrm{Al}_{2} \mathrm{O}_{3}$ in the ceramic substrate and the final reaction product $9 \mathrm{Al}_{2} \mathrm{O}_{3} \cdot \mathrm{Cr}_{2} \mathrm{O}_{3}$ is formed at the interface.

\section{Discussion}

Superalloys with different C contents show different wettabilities and interface reaction behaviors on the same ceramic substrates. As the $\mathrm{C}$ content is lower than $0.1 \mathrm{wt} . \%$, the wetting angle is around $140^{\circ}$. The large wetting angle means that the melt alloy doesn't wet the ceramic substrate and the penetration of melt alloy into ceramic substrate is difficult to occur in the casting process. As C content is higher than $0.1 \mathrm{wt} . \%$, the interface reaction takes place and the wetting angle decreases to $80^{\circ}-90^{\circ}$. The decrease of wetting angle is resulted by the following reasons. On one hand, the change of reaction energy is able to decrease $\sigma_{\mathrm{sl}}$ and wetting angle [5]. On the other hand, the compound at the interface varies because of interface reaction and then the wettability is changed $[6,7]$.

It has been reported that $\mathrm{Cr}$ in the melt alloy is able to react with $\mathrm{SiO}_{2}$ in ceramic material and the reaction equation is $3 \mathrm{SiO}_{2}+2(\mathrm{Cr}) \rightarrow 3 \mathrm{SiO} \uparrow+\mathrm{Cr}_{2} \mathrm{O}_{3}$ [8]. Furthermore, $\mathrm{Al}_{2} \mathrm{O}_{3}$ and $\mathrm{SiO}_{2}$ in ceramic material are able to react with $\mathrm{C}$ in melt alloy and the reaction equations are $\mathrm{SiO}_{2}+2(\mathrm{C}) \rightarrow \mathrm{Si}+2 \mathrm{CO} \uparrow$ and $\mathrm{Al}_{2} \mathrm{O}_{3}+3(\mathrm{C}) \rightarrow 2 \mathrm{Al}+3 \mathrm{CO} \uparrow$ [8]. To fulfill the condition of $\Delta G<0, \mathrm{SiO}_{2}+2(\mathrm{C}) \rightarrow \mathrm{Si}+2 \mathrm{CO} \uparrow$ takes place above $1573 \mathrm{~K}$ and $\mathrm{Al}_{2} \mathrm{O}_{3}+3(\mathrm{C}) \rightarrow 2 \mathrm{Al}+3 \mathrm{CO} \uparrow$ takes place above $1823 \mathrm{~K}$ [8]. Compared with the viewpoints in [8], it is the same reaction product composed of $\mathrm{Cr}_{2} \mathrm{O}_{3}$ and there is gas released from the alloy drop in the present study. However, we found that the melt alloy with different $\mathrm{C}$ contents shows different reaction behaviors on the same ceramic substrate although $\mathrm{Cr}$ content is constant in this study. 

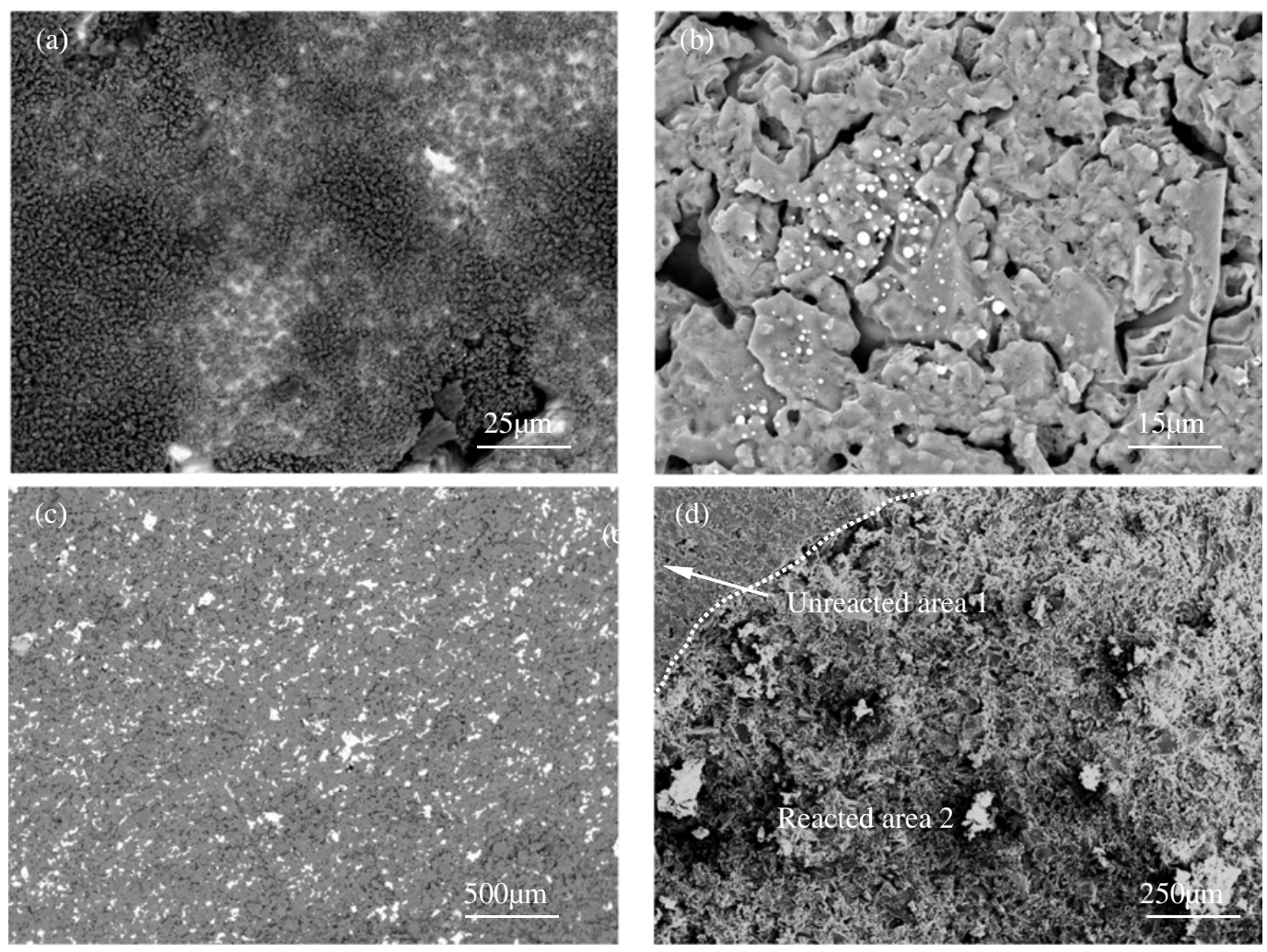

Figure 5. Microstructures on alloy drop bottom and ceramic surface. (a) and (b) the alloy drop bottom with $0.1 \mathrm{wt} . \% \mathrm{C}$ and the corresponding ceramic surface, (c) and (d) the alloy drop bottom with $0.2 \mathrm{wt} \% \mathrm{C}$ and the corresponding ceramic surface.
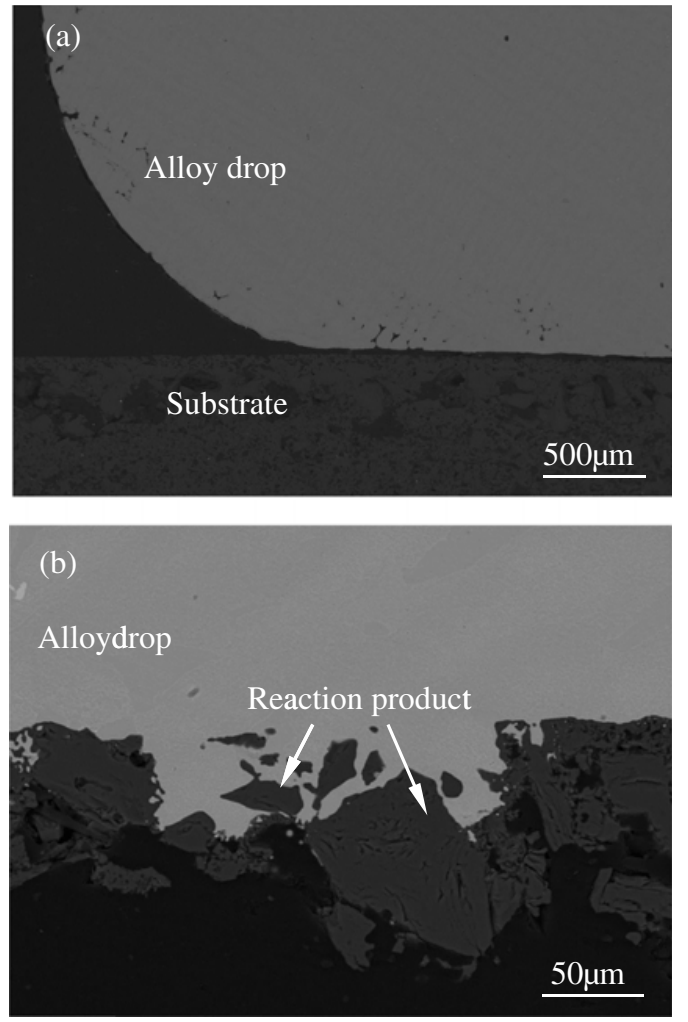

Figure 6. Interfacial microstructures between alloy drops and ceramic substrates. (a) 0.1 wt.\% C and (b) 0.2 wt.\% C.

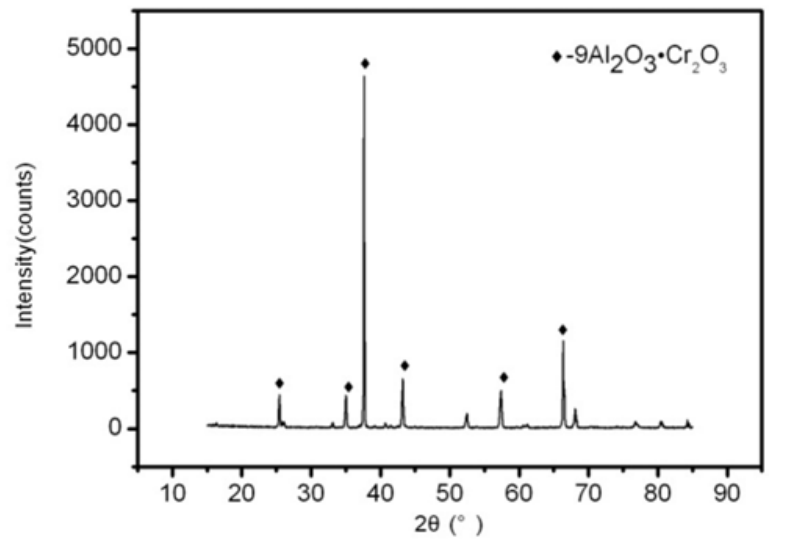

Figure 7. XRD pattern of the reaction product in the case of 0.2 wt. $\%$ C.

This indicates that $\mathrm{Cr}$ is not able to react with ceramic material without enough $\mathrm{C}$ in the melt alloy.

The reason why the interface reaction between $\mathrm{Cr}$ and ceramic material is controlled by the $\mathrm{C}$ content in the alloy melt can be explained from thermodynamics consideration and from the high instability of $\mathrm{SiO}$. According to oxygen potential diagram, $\mathrm{Cr}$ is not able to react with $\mathrm{SiO}_{2}$ to form $\mathrm{Cr}_{2} \mathrm{O}_{3}$ directly. It has been reported that $\mathrm{C}$ can react with $\mathrm{SiO}_{2}$ to form $\mathrm{CO}$ and $\mathrm{SiO}$ gases and the reaction equation is (C) $+\mathrm{SiO}_{2} \rightarrow \mathrm{SiO} \uparrow+\mathrm{CO} \uparrow$ [9]. Following this 
Table 1. Thermodynamic data used for the calculation.

\begin{tabular}{|c|c|c|c|c|}
\hline & $\mathrm{C}$ & $\mathrm{SiO}_{2}$ & $\mathrm{CO}$ & $\mathrm{SiO}$ \\
\hline$H_{298}^{\Theta} \mathrm{KJ} / \mathrm{mol}$ & 0 & -908.35 & -110.54 & -100.42 \\
\hline$S_{298}^{\Theta} \mathrm{J} / \mathrm{mol}$ & 5.74 & 43.4 & 197.55 & 211.46 \\
\hline $\mathrm{a}$ & 24.493 & 71.626 & 28.409 & 29.824 \\
\hline $\mathrm{b}$ & 0.435 & 1.891 & 4.1 & 8.238 \\
\hline $\mathrm{c}$ & -31.627 & -39.058 & -0.46 & -2.063 \\
\hline $\mathrm{d}$ & 0 & 0 & 0 & -2.28 \\
\hline $\mathrm{T} / \mathrm{K}$ & $1100-4073$ & $298-2000$ & $298-2500$ & $298-2000$ \\
\hline
\end{tabular}

idea from [9], we think that $\mathrm{SiO}$ is the initial product of reaction. After its dissolution or decomposition at the interface, large amounts of active $\mathrm{O}$ atoms are released to combine with active $\mathrm{Cr}$ atoms and form $\mathrm{Cr}_{2} \mathrm{O}_{3}$. $\mathrm{CO}$ is a kind of stable gas and it escapes from the alloy drop as the concentration of $\mathrm{CO}$ exceeds the saturation degree in the melt alloy. $\mathrm{Al}_{2} \mathrm{O}_{3}$ in the ceramic material and $\mathrm{Cr}_{2} \mathrm{O}_{3}$ finally forms $9 \mathrm{Al}_{2} \mathrm{O}_{3} \cdot \mathrm{Cr}_{2} \mathrm{O}_{3}$. The whole reaction process is illustrated by the following formula:

$$
\begin{aligned}
& (\mathrm{C})+\mathrm{SiO}_{2} \rightarrow \mathrm{SiO} \uparrow+\mathrm{CO} \uparrow \\
& \mathrm{SiO} \rightarrow(\mathrm{Si})+(\mathrm{O}) \\
& 2 \mathrm{Cr}+3(\mathrm{O}) \rightarrow \mathrm{Cr}_{2} \mathrm{O}_{3} \\
& \mathrm{Cr}_{2} \mathrm{O}_{3}+9 \mathrm{Al}_{2} \mathrm{O}_{3} \rightarrow 9 \mathrm{Al}_{2} \mathrm{O}_{3} \cdot \mathrm{Cr}_{2} \mathrm{O}_{3} .
\end{aligned}
$$

A possible chemical reaction should fulfill the thermodynamic condition of $\Delta G_{r}<0$. Thermodynamic calculations are carried out to support the formulation of the reaction process through the following formula:

$\Delta G^{\Theta}=\Delta H_{298}^{\Theta}-T \Delta S_{298}^{\Theta}+\int_{298}^{T} \Delta C_{p} d T-T \int_{298}^{T} \frac{\Delta C_{p}}{T} d T$.

Where $C_{\mathrm{p}}$ is expressed as the following formula:

$$
\begin{aligned}
C_{p}(T)= & a+b \times 10^{-3} T+c \times 10^{5} T^{-2} \\
& +d \times 10^{-6} T^{2} \mathrm{~J} / \mathrm{mol} / \mathrm{K}
\end{aligned}
$$

Thermodynamic data used in the calculation of $G_{r}$ for the equation $(\mathrm{C})+\mathrm{SiO}_{2} \rightarrow \mathrm{SiO} \uparrow+\mathrm{CO} \uparrow$ is listed in Table 1 and the calculated result is $\Delta G^{\Theta}(1823 \mathrm{~K})=50.11 \mathrm{KJ} / \mathrm{mol}$.

For a chemical reaction without gas, $\Delta_{r} G_{\mathrm{m}}=\Delta_{r} G_{\mathrm{m}}^{\Theta}$. For a chemical reaction with gas, $\Delta_{\mathrm{r}} G_{\mathrm{m}}$ is influenced by the partial pressure of the gas. For the process (C) $+\mathrm{SiO}_{2} \rightarrow \mathrm{SiO} \uparrow+\mathrm{CO} \uparrow$, because the gas pressure of $\mathrm{CO}$ and $\mathrm{SiO}$ is small and hard to measure, the accurate value of $\Delta_{r} G_{m}$ is not able to give here. However, according to inequation $3, \Delta_{\mathrm{r}} G_{\mathrm{m}}<0$ as long as $P_{\mathrm{CO}}\left(P_{\mathrm{SiO}}\right)<0.19 \times 10^{5} \mathrm{~Pa}$. In the non-in-situ and insitu experiments, the gas pressure in the furnace is $0.01 \mathrm{~Pa}$ and $5 \times 10^{-4} \mathrm{~Pa}$, respectively. Both gas pressure fulfill the requirement of $P_{\mathrm{CO}}\left(P_{\mathrm{SiO}}\right)<0.19 \times 10^{5} \mathrm{~Pa}$ and then the reaction $(\mathrm{C})+\mathrm{SiO}_{2} \rightarrow \mathrm{SiO} \uparrow+\mathrm{CO} \uparrow$ is able to take place.

$$
\Delta_{r} G_{m}=\Delta_{r} G_{m}^{\Theta}+R T \ln \frac{P_{C O} \times P_{S i O}}{\left(P^{\Theta}\right)^{2}}<0 .
$$

\section{Conclusions}

The interface reaction between superalloy melt and ceramic materials is controlled by the $\mathrm{C}$ content in the superalloys. As the $\mathrm{C}$ content is less than $0.1 \mathrm{wt} \%$, the ceramic substrate cannot be wetted by the superalloy melt and no interface reaction occurs. As the $\mathrm{C}$ content is higher than 0.1 wt. $\%$, the ceramic substrate is wetted by the superalloy melt and interface reaction takes place. The interface reaction product is composed of $9 \mathrm{Al}_{2} \mathrm{O}_{3} \cdot \mathrm{Cr}_{2} \mathrm{O}_{3}$.

$\mathrm{C}$ in the alloy is able to deoxidize $\mathrm{SiO}_{2}$ in the ceramic material and produce $\mathrm{SiO}$ and $\mathrm{CO}$. $\mathrm{SiO}$ releases active $\mathrm{O}$ atom, $\mathrm{Cr}$ in the alloy melt combines with the active $\mathrm{O}$ atom and $\mathrm{Cr}_{2} \mathrm{O}_{3} \cdot \mathrm{Al}_{2} \mathrm{O}_{3}$ in the ceramic material and $\mathrm{Cr}_{2} \mathrm{O}_{3}$ finally forms $9 \mathrm{Al}_{2} \mathrm{O}_{3} \cdot \mathrm{Cr}_{2} \mathrm{O}_{3}$.

This work was supported by the National Natural Science Foundation of China (Grant Nos. 51271186, U1037601, 50931004, 51204156 and 51101153).

\section{References}

[1] Q. Li, J. X. Song, D. G. Wang, Q. Yu and C. B. Xiao. Rare.Metals. 30, Spec. (2011)

[2] L. Zheng, C. B. Xiao, G. Q. Zhang, G. H. Gu, X. Li, X. G. Liu, M. Xue and D. Z. Tang. J. Aero. Mater. 32, 3 (2012)

[3] M. R. Orlov. Russ. Metall. 2008, 1 (2008)

[4] F. Valenza, M. L. Muolo and A. Passerone. J. Mater. Sci. 45, 8 (2010)

[5] I. A. Aksay, C. E. Hoge and J. A. Pask. J. Phys. Chem. 78, 12 (1974)

[6] N. Eustathopoulos, M. G. Nicholas and B. Drevet. Wettability at High Ttemperatures (Elsevier Science, Oxford, 1999)

[7] V. Laurent, D. Chatain and N. Eustathopoulos. Mater. Sci. Eng. A. 135, 1-2 (1991)

[8] X. F. Liu, W. J. Guo, Y. C. Lou, G. Q. Su and B. Yu. Foundry. 59, 12 (2010)

[9] J. R. Li, J. C. Xiong, D. Z. Tang. Advanced high temperature structural materials and technology (NDIP, Beijing, 2012) 